\title{
AC 2010-1495: POWER CONVERSION COURSEWORK USING A SOLID STATE TESLA COIL
}

\section{Justin Reed, University of Wisconsin, Madison}

Justin Reed received the B.S. degree in electrical engineering from the University of Washington, Seattle in 2005 and the M.S. degree in electrical engineering from the University of Wisconsin, Madison in 2008. He is currently working towards the Ph.D. degree in electrical engineering at the Wisconsin Electric Machines and Power Electronics Consortium (WEMPEC), where he has experience as a teaching assistant for several electrical engineering courses. His interests include engineering education, power electronics, motors and renewable energy applications.

\section{Daniel Ludois, University of Wisconsin, Madison}

Dan Ludois received the B.S. degree in physics from Bradley University in Peoria, IL in 2006 and the M.S. degree in electrical engineering from the University of Wisconsin, Madison in 2008. $\mathrm{He}$ is currently working towards the Ph.D. degree in electrical engineering at the Wisconsin Electric Machines and Power Electronics Consortium (WEMPEC). Dan has several years of experience as a teaching assistant for electromagnetics, power conversion and renewable energy courses. In addition to engineering education, Dan's interests include power electronics, electric machines and applied electromagnetics.

\section{Maria Hamlin, University of Wisconsin, Milwaukee}

Maria Hamlin is an assistant professor of Science Education at the University of Wisconsin-Milwaukee in the Department of Curriculum and Instruction. Her research interests include equity and access issues in mathematics and science, STEM initiatives, multicultural mathematics and science education. Dr. Hamlin earned her B.A.S. in Teaching Mathematics from the University of Minnesota-Duluth. She completed her M.S. in Science Education, M.S. in Ecology and Evolutionary Biology, and her Ph.D. in Educational Studies at the University of Michigan. 


\section{Power Conversion Coursework Using a Solid State Tesla Coil}

\section{Introduction}

Comprehensive electrical engineering curricula involve both analytical design and experimental components. In the area of power electronics, these components can be integrated using a sample application of the course material such as a buck or boost converter. This converter is then gradually analyzed and/or designed during the course using open-ended homework questions for teaching students valuable problem solving skills in addition to the core course material. Coupled with the physical construction of the sample application throughout the duration of the course, the students receive an education rich in both theoretical and practical scopes.

The authors recently designed and constructed a solid state Tesla coil (or SSTC, shown in Figure 1) for use in demonstrations to stimulate K-12 interest in science, technology, engineering, and mathematics (STEM) fields. In response to the subsequent interest of both practicing engineers and college engineering students in the SSTC, this paper proposes its use as a sample application in a power conversion course.

Tesla coils have long been used in physics demonstrations to engage audiences and rouse interest in the sciences and engineering. More recently, solid state power electronics have been used to drive Tesla coils, allowing much greater control over the arcs and permitting the production of music with their plasmas. It is expected, then, that the use of an SSTC in a power electronics or other power conversion course could improve student engagement throughout the course as compared to more conventional sample applications. Furthermore, it will be shown that the knowledge base necessary to build an SSTC spans far more technical areas than required in most conventional power electronics projects, and therefore justifies the SSTC as practical classroom exercise. The hypotheses presented in this paper are investigated and further evaluated with a survey to gauge student interest in enrolling in a power electronics course based on a variety of sample applications, including the SSTC.

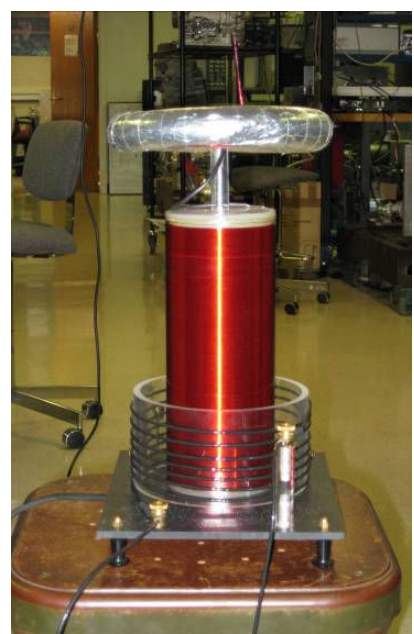

(a)

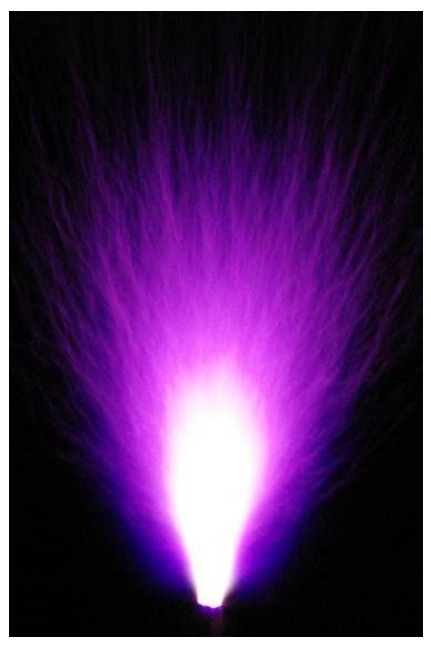

(b)

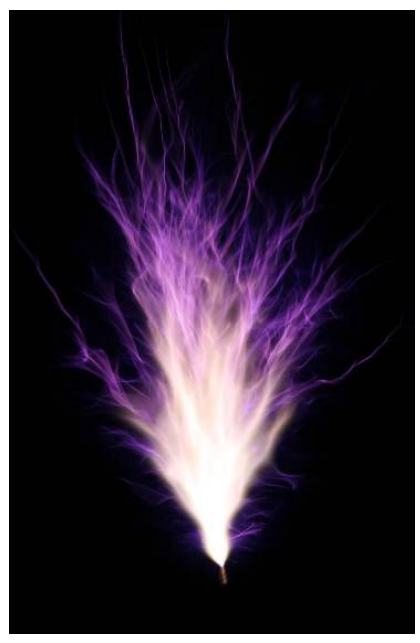

(c)

Figure 1: Solid state Tesla coil. (a) Actual Tesla coil used in this paper, (b-c) examples of plasma effects seen during operation (photography by Tim Obermann). 
This paper first discusses the educational aspects of the proposed course structure in the Educational Theory section, which motivates the general integration of power converter sample applications in suggested curricula. Motivation for choosing the SSTC specifically, from student interest and instructor perspectives, is provided by the survey-based research discussed in the Application Influence and Choice section. The inner workings of the SSTC are then outlined in the SSTC Circuits and Curriculum section. The lecture content and proposed 16-week SSTCbased curriculum complete with homework assignments and in-class demonstrations are then presented with discussions of laboratory components. A brief summary concludes the work.

\section{Educational Theory}

Electrical engineering courses tend to be highly theoretical and require students to place emphasis on relatively abstract conceptualizations ${ }^{1}$. Because of this, these courses traditionally have been taught using a subject-based learning (SBL) approach which does not require active participation on the part of the student ${ }^{2}$. In an effort to provide a more student-centered experience, one that engages learners in more application-based experiences, a problem-based learning approach is proposed for incorporation into power electronics courses.

Problem-based learning (PBL) requires the instructor to place students' needs at the forefront of instructional decisions and provides opportunities for students to actively participate in their own learning ${ }^{4}$. Generally, when PBL is employed within the classroom, students are posed a problem, required to identify the information they will need to know to solve the problem, engage in self directed study to learn the material and apply the new knowledge they acquire by finding a solution to the problem, and then must be able to summarize and integrate what they have learned and apply this to additional problems and/or contexts ${ }^{5}$. PBL enables students to work on professional problems of practice and provides opportunities for students to formulate and solve problems they may encounter later during their employment ${ }^{6,7}$.

There are many additional benefits to PBL such as promoting autonomous learning, requiring high levels of analytical thinking, providing greater opportunities for collaboration, communication and task management, as well as opportunities for students to present logical arguments for their solutions ${ }^{8,9,10}$. However, despite its many educational benefits, PBL can be logistically difficult to implement. For example, some courses are offered simultaneously to oncampus and off-campus students through live and online lectures, respectively. Students located off campus are unable to participate in the group work of a PBL course due to their decentralized nature, and therefore PBL presents a challenge to these students.

This paper's proposed coursework uses a hybrid of SBL and PBL. More precisely, this paper proposes an electrical power conversion course that includes conventional lectures and individual homework assignments, similar to SBL, and emphasizes the use of problems that do not have clear answers to enhance students' problem solving skills. Furthermore, discussions between students regarding their understanding of the material (but not homework solutions) are highly encouraged, another tenet of PBL.

Homework assignments and lecture material are centered around the use of a sample application of electrical power conversion technology that encourages system-level thinking by the students 
instead of a collection of discrete power conversion components. The effects of the application choice and student opinions regarding several potential applications are evaluated in the next section.

\section{Application Influence and Choice}

In order to evaluate the effect of various application-based curricula on student interest and engagement, a survey was given to 2 groups of students. Group A comprised 64 undergraduate mechanical engineering students, most in junior or senior standing, who were enrolled in an electromechanical energy conversion course. Group B comprised 21 students, mostly electrical engineers, enrolled in either a beginning power systems course or a beginning electrical drives course. Both undergraduate seniors and first-year graduate students composed this group.

Student interest and engagement were evaluated in the survey using direct questions on these topics with simplifying terminology. For example, using the term "application-based curriculum" to signify the PBL-influenced educational approach outlined in the previous section, participants responded to questions such as "compared to courses without application-based curricula, please indicate how much having an application-based curriculum affected (or how you would expect it to affect) your engagement in the course," and "how much does the choice of application affect (or how would you expect it to affect) your engagement in the course." Identically formed questions asked about their interest in the course material as well. A copy of the survey questions is provided in the Appendix for reference.

The results were overwhelmingly positive. Specifically, $72 \%$ of the group A respondents and $81 \%$ of the group B respondents said that having a PBL-influenced curriculum would have a positive effect on their engagement in the course. Similarly, $80 \%$ of group A and $81 \%$ of group B said that a PBL-influenced curriculum would positively affect their interest in the course material. When asked if, overall, having courses with PBL-influenced curricula are beneficial to the students, $77 \%$ of group A and $76 \%$ of group B claimed they would benefit.

Participants indicated and identified differences in the quality of the applications. $78 \%$ of group A and $76 \%$ of group B said that some applications were better than others, however there was significant disparity regarding which applications are best. Respondents were provided with seven applications and asked to rank them in order of preference for study. These choices were: a solar-powered AA battery charger, a 100A arc welder, a 500W DC motor drive/controller, a $120 \mathrm{~V}$ Uninterruptable Power Supply (UPS), a 100kV musical Tesla coil, a 5V/12V DC buck or boost converter, and a 20V DC laptop power supply.

Histogram representations of the same results for groups A and B are shown in Figure 2 and Figure 3, respectively. These figures show how many times each application was given a certain ranking of preference. For example, a large number of respondents in group A gave a very high ranking of preference ( 1 or 2$)$ to the solar battery charger, while very few gave the laptop power supply the same ranking. Likewise, the buck or boost converter was often given a poor ranking of preference by group A, while group B was somewhat less opinionated on this application, indicated by more dispersed results. 


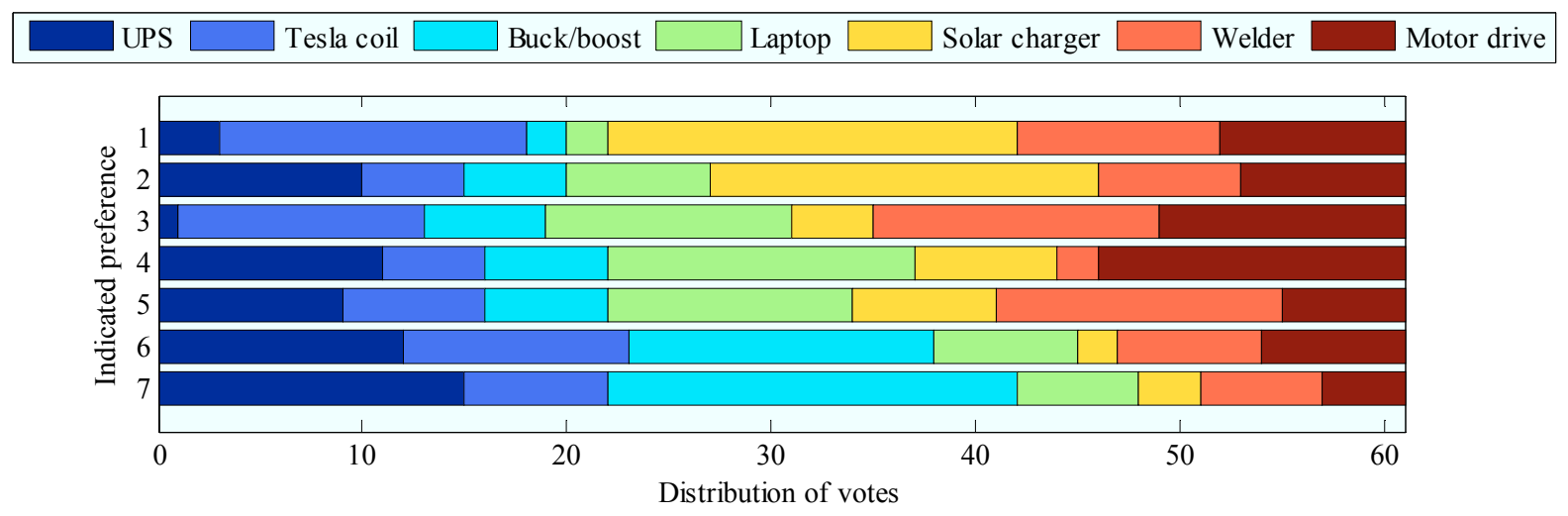

Figure 2: Histogram of group A results $(1=$ most preferred, 7 = least preferred).

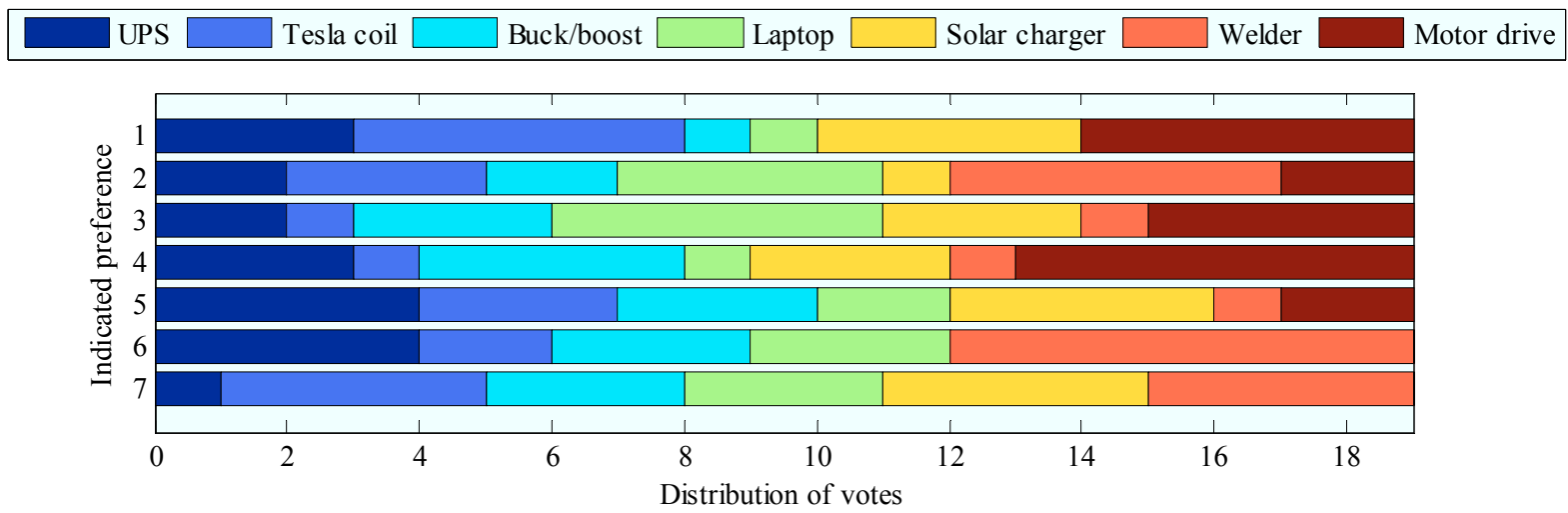

Figure 3: Histogram of group B results $(1=$ most preferred, $7=$ least preferred $)$.

The survey also indicated that practicality is a serious concern for the students. When asked if "having courses with [PBL-influenced] curricula is beneficial to... the student," many respondents indicated that theory was important, however learning practical information that they can use in industry is just as important. This was corroborated with answers to "what most drives your interest in an engineering course," which showed that students have a very strong preference for courses with practical value (see Figure 4). Interestingly, the students' desire for what may be termed "practical educational value" can also prevent them from obtaining it. For example, although the SSTC was second to the solar AA battery charger in both groups, presumably due to the charger's superior practical value, an instructor would likely feel the appropriate choice is the SSTC. As will be demonstrated in the following section, the SSTC combines several power converter topologies into a single project of breadth and scope that the other projects, including the solar AA battery charger, cannot meet. It is this combination of student interest and the instructor experience that yields the best choice for a classroom application.

Several conclusions can be drawn from these survey results:

- students do show preferences for certain applications over others;

- this preference varies among the student groups (e.g. mechanical vs. electrical engineers);

- a significant number of students in both groups find the SSTC to be a preferable option;

- and the material taught in the course must have practical value, regardless of which application is ultimately chosen for the course. 


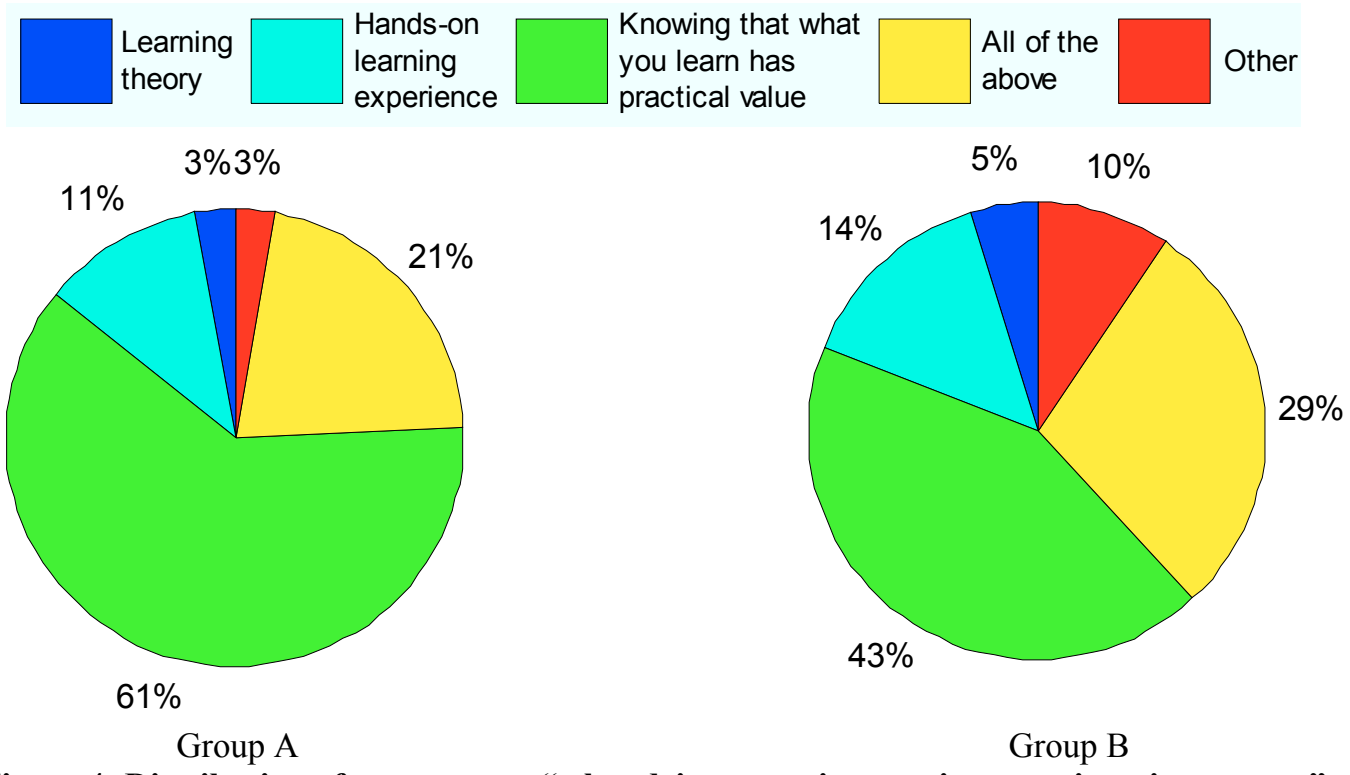

Figure 4: Distribution of responses to "what drives your interest in an engineering course."

\section{SSTC Circuits and Curriculum}

The SSTC has now been shown to rouse student interest, and in this section its practical value as a teaching tool will be developed by presenting its circuitry and proposing a power electronics course curriculum. Although the SSTC may seem like a complete novelty in terms of its purpose as a high voltage generator and speaker, this section shows that the curriculum will contain a great deal of practical information. This is due to the SSTC's construction, which is based off of several extremely common and practical power converter topologies. Thus, even though these topologies are combined in a manner that might rarely be used by the students in industry, the educational value they gain by working with the topologies would enable them to work with virtually any real power converters in use today and the foreseeable future.

The SSTC circuits are now shown and a 16 week power electronics curriculum designed around the SSTC is proposed. The course structure is separated into several distinct areas: lecture, homework assignments and in-class demonstrations, and an optional bi-weekly lab.

\section{SSTC Architecture}

Classical Tesla coils (TCs) use a high voltage transformer to drive a spark-gap switched resonant tank circuit. Modern day power electronics devices such as MOSFETs may replace the spark gap technology, allowing for a relatively low primary voltage and unparalleled control capability $^{13}$. The power electronics topology is shown in Figure 4 and the TC equivalent circuit model used in the SSTC is shown in Figure 5.

Stage 1 of the power electronic circuit is a simple 3-phase rectifier $\mathrm{D}_{\mathrm{B} 1}$ in series with pre-charge and main contactors connected to a $\mathrm{DC}$ bus capacitor $\mathrm{C}_{1}$. Stages 2-4 compose a high frequency isolated DC-DC converter, which provides a means of controlling the DC bus voltage of the high frequency full bridge converter in Stage 5. Stage 2 is a full bridge DC-AC converter, which chops the Stage $1 \mathrm{DC}$ output into a $20 \mathrm{kHz}$ square wave of adjustable duty cycle and feeds the 
high frequency transformer $T_{1}$ in Stage 3 . Depending on design specifics, $T_{1}$ may possess an arbitrary turns ratio but in most cases is 1:1. Stage 4 rectifies the output of $T_{1}$ via ultra-fast diodes onto $\mathrm{DC}$ bus capacitor $\mathrm{C}_{2}$. It should be noted that this capacitor can be much smaller than $\mathrm{C}_{1}$ due to the much higher fundamental frequency. Finally, Stage 5 chops up the Stage 4 DC output into a $250-300 \mathrm{kHz}$ square wave to drive the TC. Note the extra diodes in the Stage 5 converter, which prevent MOSFET body diode conduction. External ultra-fast diodes were added to reduce reverse recovery effects, and thus losses, at this very high switching frequency.

The TC itself is an air core resonant transformer consisting of primary and secondary windings and a top-load capacitance. The secondary coil is designed such that the length of wire wrapped around the coil form is $1 / 4$ the wavelength of the operating frequency. The operating frequency refers to the resonant frequency established by the secondary winding self inductance $\mathrm{L}_{\mathrm{s}}$ and topload capacitance $C_{p s}$ (ball, sphere, torus, etc.) with respect to ground. Stage 5 of the power converter drives the primary coil at the secondary coil resonant frequency to achieve a high voltage display, in the neighborhood of $100 \mathrm{kV}$. The duty cycle is then modulated using phase shift modulation, which affects the size of the plasma on the output (higher duty cycles create larger plasmas). Modulating the duty cycle with an audio source produces plasmas oscillating at those frequencies, which in turn creates pressure waves, and thus sound.

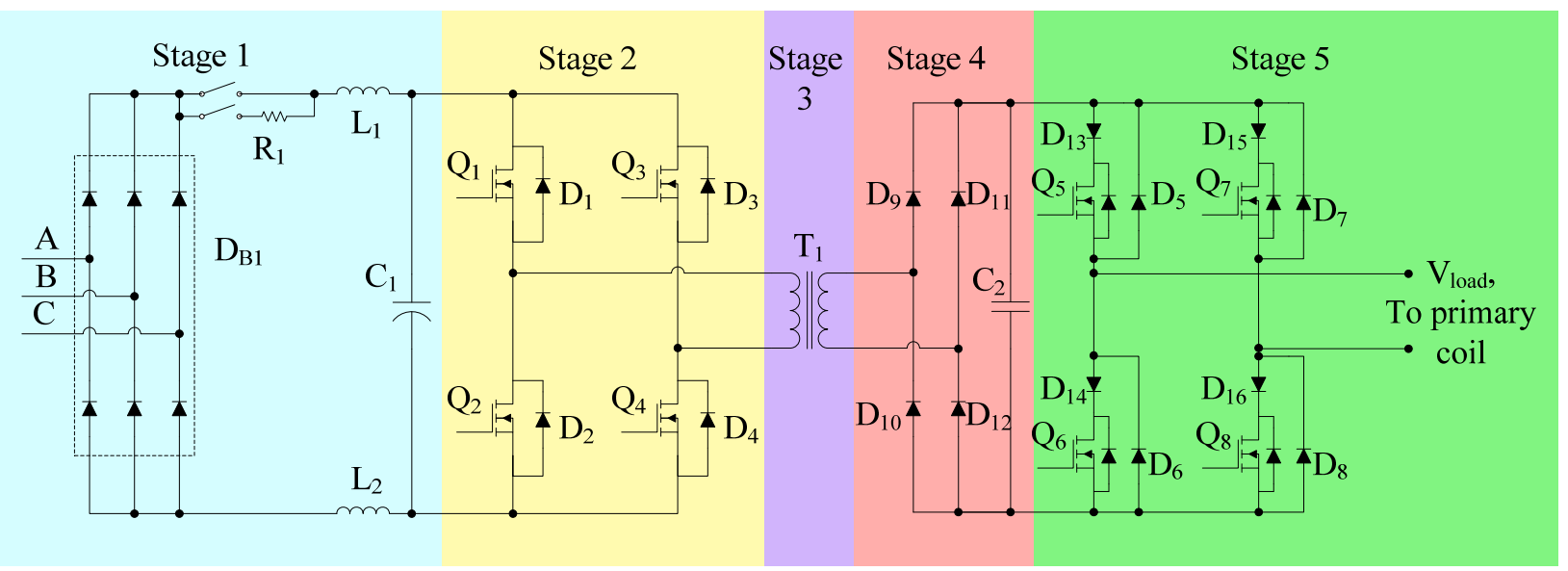

Figure 4: Power electronics schematic, separated into stages.

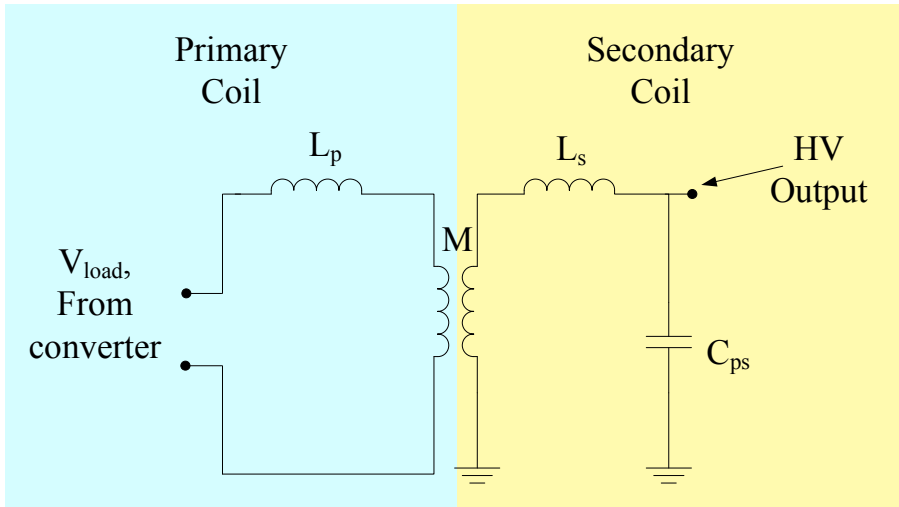

Figure 5: Tesla coil primary and secondary coil lumped circuit model. 
The SSTC clearly contains a wealth of potential course material related to both power electronics and electromagnetics. In these two categories, the SSTC can be coupled with course content in: ferrous and air-core transformers, quarter-wave length resonators, high voltage engineering concepts, low and high frequency power conversion such as rectifiers and full bridge inverters, switching devices, modulation techniques, and thermal design to name a few. These topics make it evident that the design and construction of a SSTC provides an exciting avenue for presenting course content rich in the essentials of power conversion and is therefore appropriate for use in the classroom.

\section{Lecture}

Like most courses, the lecture begins with the fundamental concepts of power electronics and further builds upon them as the semester progresses. Power electronics circuits mainly consist of two basic types of components: semiconductor switches and passive energy storage devices. Table 1 lists the core areas of power electronics theory, roughly divided into these categories, and all of which apply to the SSTC. The lecture may also be divided into the 5 stages of the power converter as well as the electromagnetic structure of the coil.

Table 1: Lecture content

\begin{tabular}{|c|c|}
\hline $\begin{array}{l}\text { Power Electronics Devices \& Control } \\
\text { - } \\
\text { - Rectifiers } \\
\text { - } \text { Binear regulators } \\
\text { - Switchitching theory } \\
\text { ○ AC-DC } \\
\text { ○ DC-DC } \\
\text { ○ AC-AC } \\
\text { - Types of semiconductors } \\
\text { - Semiconductor losses } \\
\text { - Control theory } \\
\text { - } \text { Modulation techniques }\end{array}$ & 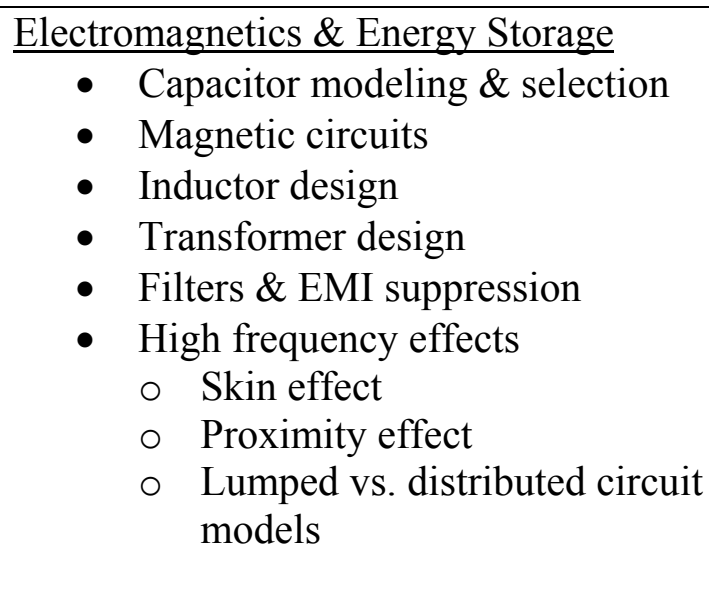 \\
\hline
\end{tabular}

\section{Homework and In-Class Demonstrations}

Keeping with the PBL-influenced SBL teaching method, homework assignments are designed such that each week the students will complete an open-ended design and analysis problem regarding the SSTC. These assignments will directly correspond to the material learned in the week's lectures as well as the stages of the SSTC. Each stage of the SSTC power converter is progressively more complex than the last, further challenging the student as the semester progresses. After the completion of each assignment, the instructor will use the SSTC to illustrate the results or lesson of the homework assignment. An example of this would be to use an oscilloscope to demonstrate the actual voltage, current, and switching logic waveforms students should have generated in their own analysis. A thermal measurement device could also be used to measure temperature rise of the semiconductors to compare thermal results as well. Table 2 illustrates an example curriculum using the SSTC for a 16 week semester. 
Table 2: Suggested homework and demonstration schedule based on a 16-week semester

\begin{tabular}{|c|c|c|}
\hline & Homework Assignment & Demonstration \\
\hline Week 1 & Linear regulator analysis & $\begin{array}{l}\text { Bring in examples of linear regulators and } \\
\text { their use }\end{array}$ \\
\hline Week 2 & $\begin{array}{l}\text { Stage } 13 \text {-ph rectifier, obtain necessary model, } \\
\text { waveforms \& capacitor sizing }\end{array}$ & $\begin{array}{l}\text { Demonstrate Stage } 1 \text { waveforms on } \\
\text { oscilloscope in class }\end{array}$ \\
\hline Week 3 & $\begin{array}{l}\text { Stage } 2 \text { full bridge design, obtain necessary } \\
\text { model, waveforms \& switching functions. }\end{array}$ & $\begin{array}{l}\text { Demonstrate Stage } 2 \text { waveforms on } \\
\text { oscilloscope in class }\end{array}$ \\
\hline Week 4 & $\begin{array}{l}\text { Stage } 1 \& 2 \text { semiconductor selection } \& \text { loss } \\
\text { calculation. Provide actual part numbers and } \\
\text { data to back your selection }\end{array}$ & $\begin{array}{l}\text { Demonstrate actual semiconductor devices } \\
\text { and use thermal camera to show losses in } \\
\text { stages 1-2 }\end{array}$ \\
\hline Week 5 & $\begin{array}{l}\text { Stage } 3 \text { transformer design, determine core } \\
\text { dimensions, turn count, wire gauges, \& candidate } \\
\text { core part number }\end{array}$ & $\begin{array}{l}\text { Demonstrate Stage } 3 \text { waveforms on } \\
\text { oscilloscope in class along with various } \\
\text { transformers used in dc-dc converters }\end{array}$ \\
\hline Week 6 & $\begin{array}{l}\text { Stage } 4 \text { 1-ph rectifier design, obtain necessary } \\
\text { waveforms \& capacitor sizing with high } \\
\text { frequency operation considerations }\end{array}$ & $\begin{array}{l}\text { Demonstrate Stage } 4 \text { waveforms on } \\
\text { oscilloscope in class }\end{array}$ \\
\hline Week 7 & No Homework - Midterm Exam week & None \\
\hline Week 8 & $\begin{array}{l}\text { Stage } 5 \text { full bridge design, obtain necessary } \\
\text { model, waveforms, \& switching functions. }\end{array}$ & $\begin{array}{l}\text { Demonstrate Stage } 5 \text { waveforms on } \\
\text { oscilloscope in class }\end{array}$ \\
\hline Week 9 & $\begin{array}{l}\text { Stage } 4 \& 5 \text { semiconductor selection } \& \text { loss } \\
\text { calculation, with high frequency considerations }\end{array}$ & $\begin{array}{l}\text { Demonstrate actual semiconductor devices } \\
\text { and use thermal camera to show losses in } \\
\text { stages 4-5 }\end{array}$ \\
\hline Week 10 & $\begin{array}{l}\text { Design voltage regulator for dc-dc converter } \\
\text { Stages } 2-4 \text {. Block diagram, transfer function, } \\
\text { Bode plot, etc. }\end{array}$ & $\begin{array}{l}\text { Demonstrate controller transfer function } \\
\text { with signal analyzer. Feedback sensors, } \\
\text { error measurement, PI gains }\end{array}$ \\
\hline Week 11 & $\begin{array}{l}\text { Design Stage } 5 \text { current regulator \& resonance } \\
\text { tracking. Block diagram, transfer function, Bode } \\
\text { plot, etc. }\end{array}$ & $\begin{array}{l}\text { Demonstrate controller transfer function } \\
\text { with signal analyzer. Feedback sensors, } \\
\text { error measurement, PI gains }\end{array}$ \\
\hline Week 12 & $\begin{array}{l}\text { Design air core resonator for } 300 \mathrm{kHz} \text { operation } \\
\text { and given power throughput using lumped circuit } \\
\text { elements }\end{array}$ & $\begin{array}{l}\text { Bring primary and secondary coil to class, } \\
\text { discuss HV design points, point out } \\
\text { distributed circuit element approach }\end{array}$ \\
\hline Week 13 & $\begin{array}{l}\text { Design an analog modulation scheme to } \\
\text { incorporate an audio source in state } 5\end{array}$ & $\begin{array}{l}\text { Use oscilloscope to demonstrate stage } 5 \\
\text { voltage modulation and use Tesla coil to } \\
\text { play music }\end{array}$ \\
\hline Week 14 & Special topics - extra credit & $\begin{array}{l}\text { Instructor's choice, i.e. motor drive from } \\
\text { optional lab section. }\end{array}$ \\
\hline Week 15 & No Homework - Study week & None \\
\hline Week 16 & No Homework - Final Exam & None \\
\hline
\end{tabular}

\section{Laboratory Component}

It is important to note that the power electronics topological structure of several of the proposed applications in the Application Influence and Choice section are similar, particularly the SSTC and motor drive, as both are based on full bridge topologies. The small DC motor drive was also quite popular with the students in the survey since it has a "practical application." Since the SSTC as a whole is relatively complex with a high parts count and has significant control circuit requirements, a simple DC motor drive makes a good laboratory component for the course. The power electronics topology for such a drive would be a full bridge converter, equivalent to Stage 2 in Figure 4. Instead of an AC rectifier, the bridge could be driven by a battery allowing the students to apply their lab project to a wider variety of applications and at a relatively safe voltage level. 


\section{Summary}

This paper has presented an SSTC for use as a sample application of power electronics in a power conversion course. Benefits of the SSTC include a wide breadth of curriculum topics and increased student interest compared to conventional buck and/or boost converters. The educational theory of its proposed use in a classroom setting was a hybrid of SBL and PBL. PBL was strongly emphasized through the use of the applications and open-ended homework problems to encourage self-directed thinking and autonomous learning. Survey-based research performed on two groups of engineering students concluded that the SSTC was a viable option for use in the classroom, and that the course material must be practical for use in industry jobs. Details of the SSTC theory of operation and its construction were provided, showing ample potential for classroom and coursework use. A 16-week course outline based on the SSTC including homework assignments, in-class demonstrations, and an optional laboratory component were proposed. Based on the presented information and research results, the proposed coursework can be expected to enhance the students' quality of education in a power conversion course.

\section{Acknowledgments}

The authors gratefully acknowledge support from Wisconsin Electric Machines and Power Electronics Consortium (WEMPEC) and donations from Advanced Circuits, Electronic Concepts, Inc., and LEM in the construction of the SSTC. Particular thanks are extended to Frank Bayer, Neal Clements, Ray Marion, Tim Obermann, and Professors Tom Jahns and Bernie Lesieutre for their assistance.

\section{Appendix}

The following 2 pages contain the survey questions used in this study. 


\section{Power Electronics Coursework Survey}

Please take a few moments to complete this educational survey. Thanks and we greatly appreciate your honest input!

1. What most drives your interest in an engineering course?
a. Learning theory
b. A hands-on laboratory experience
c. Knowing that what you learn has practical value
d. All of the above
e. Other (specify:

2. Which teaching tools help you learn most? Please rank the following from greatest (5) to least (1), using each number only once.
a. Classroom Demonstrations
b. Homework \& Analytical Proofs
c. Field trips \& guest speakers
d. Class Projects
e. Group Work

3. What are you most interested in? Please rank the following from greatest (5) to least (1), using each number only once.
a. Industry or "Real world" applications
b. Inter-collegiate competitions
c. Humanitarian efforts
d. Group work, team building
e. Grades

4. Do you think power electronics will play an important role in your engineering career?
a. Extremely important
b. Very important
c. Important
d. Slightly important
e. Not very important

Most course are taught using problem sets for each separate topic. Imagine that you are taking a course that instead teaches theory and assigns problem sets based around one specific application of the technology from the class. For example, a course on hydraulics that teaches theory using the Boeing 777 hydraulic systems throughout the entire class. 
Several possible power electronics coursework applications are shown below:

a. Uninterruptable power supply (UPS) (120V AC with $12 \mathrm{~V}$ battery)

b. "Musical lightning" Tesla coil $(100 \mathrm{kV})$

c. Buck or Boost converter $(12 \mathrm{~V} \leftarrow \rightarrow 5 \mathrm{~V})$

d. Laptop power supply $(120 \mathrm{~V} \rightarrow 20 \mathrm{~V})$

e. Solar-powered battery charger (AA batteries)

f. $\operatorname{Arc}$ welder $(120 \mathrm{~V} \rightarrow 100 \mathrm{~A})$

g. Small electric motor controller (500W power rating)

4. Please rank the applications in order of preference to study in class from least to most interesting.

(least interesting)

(indifferent)

(most interesting)

5. Have you ever taken a course with a curriculum based on a specific application (such as an application like those listed above)? Circle yes or no

Yes / No

6. Compared to courses without application-based curricula, please indicate how much having an application-based curriculum affected (or how you would expect it to affect):

$(1=$ Very negatively, $3=$ No effect, $5=$ Very positively $)$

$\begin{array}{llllll}\text { Your engagement in the course } & 1 & 2 & 3 & 4 & 5\end{array}$

$\begin{array}{lllllll}\text { Your interest in the course material } & 1 & 2 & 3 & 4 & 5\end{array}$

7. How much does the choice of application affect (or how you would expect it to affect):

$(1=$ Not affected at all, $3=$ Affected, $5=$ Extremely

affected)

$\begin{array}{lllllll}\text { Your engagement in a course } & 1 & 2 & 3 & 4 & 5\end{array}$

$\begin{array}{lllllll}\text { Your interest in the course material } & 1 & 2 & 3 & 4 & 5\end{array}$

8. Overall, would you say that having an application-based curriculum is beneficial to you as a student (compared to the conventional alternative)? Why or why not?

9. Overall, would you say that some applications would be more beneficial than others? Why or why not?

10. If yes, which application(s) in the above list would be the most beneficial to you as a student? Why? 


\section{References}

${ }^{1}$ Becher, T. and Trowler, P., Academic Tribes and Territories: intellectual enquiry and the cultures of disciplines (2nd edition). Buckingham: Open University Press/SRHE, 2001.

${ }^{2}$ Savin-Baden, M. and Howell Major, C., Foundations of problem-based learning. Maidenhead: SRHE/ Open University Press, 2004.

${ }^{4}$ Grabinger R. S., Dunlap J. C., and Duffield J. "Student-centered learning environments in action: Problem-based learning." Association for Learning Technology Journal (ALT-J), 5(2), (1997) 5-17.

${ }^{5}$ Barrows, H. S. (1984). "A specific, problem-based, selfdirected learning method designed to teach medical problem-solving skills, self-learning skills and enhance knowledge retention and recall." Tutorials in Problem Based Learning. Editied by H.Schmidt \& M. deVolder. Maastricht, Netherlands:Van Gorcum (1984) (pp. 16-32).

${ }^{6}$ Dunlap, J.C. "Problem-Based Learning and Self-Efficacy: How a Capstone Course Prepares Students for a Profession." Educational Technology Research and Development, 53(1) (2005).

${ }^{7}$ M. H. Elahiniaa and C. Ciocanel. "A problem-solving approach for teaching engineering laboratories." Proceedings of the 2008 American Society for Engineering Education Pacific Southwest Annual Conference. (2008) ${ }^{8}$ J. E. Mitchell, and J. Smith. "Case study of the introduction of problem-based learning in electronic engineering." International Journal of Electrical Engineering Education . 45(2), (2008).

${ }^{9}$ B. Canavan. "A summary of the findings from an evaluation of problem-based learning carried out at three UK universities." International Journal of Electrical Engineering Education 45(2), (2008) 175-180.

${ }^{10}$ Powell, Norman J., Hicks, Peter J., Truscott, William S., Green, Peter R., Peaker, Anthony R., Renfrew, Alasdair and Brian Canavan. "Four case studies of adapting enquiry-based learning Enquiry Based Learning in electrical and electronic engineering." International Journal of Electrical Engineering Education, 45(2), (2008).

${ }^{13}$ Mohan, Ned and Undeland, Tore and Robbins, William. Power Electronics: Converters, Applications and Design. New York: John Wiley \& Sons, 2002. 